\title{
Correction to: Akt/FoxM1 signaling pathway-mediated upregulation of MYBL2 promotes progression of human glioma
}

\author{
Xue Zhang ${ }^{1,2}$, Qiao-Li LV ${ }^{1,2}$, Yuan-Tao Huang ${ }^{1,2,3}$, Li-Hua Zhang ${ }^{1,2}$ and Hong-Hao Zhou ${ }^{1,2^{*}}$
}

\author{
Correction to: J Exp Clin Cancer Res 36, 105 (2017) \\ https://doi.org/10.1186/s13046-017-0573-6
}

Following publication of the original article [1], the authors identified some minor errors in image-typesetting in Fig. 6; specifically in Fig. 6b which displays pictures of Hoechst 3342, a duplicate picture of the si-M was mistakenly used for the si-F.

The corrected figure is given below. The correction does not have any effect on the results or conclusions of the paper. The original article has been updated.

\section{Author details}

${ }^{1}$ Department of Clinical Pharmacology, Xiangya Hospital, Central South University, Changsha 410008, Hunan, People's Republic of China. ${ }^{2}$ Hunan Key Laboratory of Pharmacogenetics, Institute of Clinical Pharmacology, Central South University, Changsha 410078, Hunan, People's Republic of China.

${ }^{3}$ Department of Neurology, The Brain Hospital of Hunan Province, Changsha 410007, Hunan, People's Republic of China.

Published online: 02 June 2021

\section{Reference}

\footnotetext{
1. Zhang X, LV QL, Huang YT, et al. Akt/FoxM1 signaling pathway-mediated upregulation of MYBL2 promotes progression of human glioma. J Exp Clin Cancer Res. 2017;36(1):105. https://doi.org/10.1186/s13046-017-0573-6.
}

The original article can be found online at https://doi.org/10.1186/s13046017-0573-6.

* Correspondence: hhzhou2003@163.com

${ }^{1}$ Department of Clinical Pharmacology, Xiangya Hospital, Central South University, Changsha 410008, Hunan, People's Republic of China

${ }^{2}$ Hunan Key Laboratory of Pharmacogenetics, Institute of Clinical Pharmacology, Central South University, Changsha 410078, Hunan, People's Republic of China

C C The Author(s). 2021 Open Access This article is licensed under a Creative Commons Attribution 4.0 International License, which permits use, sharing, adaptation, distribution and reproduction in any medium or format, as long as you give appropriate credit to the original author(s) and the source, provide a link to the Creative Commons licence, and indicate if changes were made. The images or other third party material in this article are included in the article's Creative Commons licence, unless indicated otherwise in a credit line to the material. If material is not included in the article's Creative Commons licence and your intended use is not permitted by statutory regulation or exceeds the permitted use, you will need to obtain permission directly from the copyright holder. To view a copy of this licence, visit http://creativecommons.org/licenses/by/4.0/ The Creative Commons Public Domain Dedication waiver (http://creativecommons.org/publicdomain/zero/1.0/) applies to the data made available in this article, unless otherwise stated in a credit line to the data. 


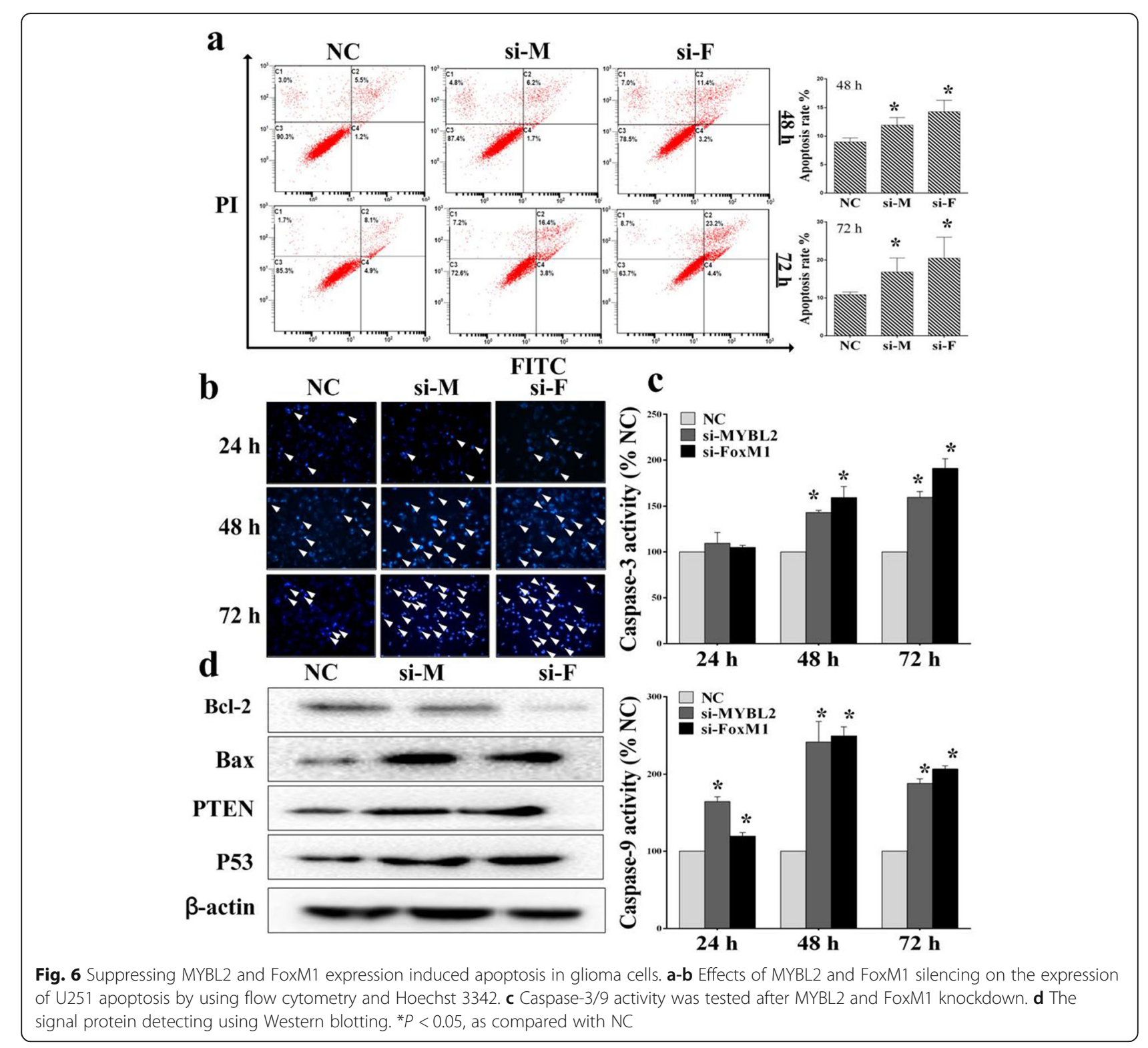

